\title{
A Simple and Flexible Method for Ranking Severe Weather Events
}

\author{
C. A. Doswell III \\ Cooperative Institute for Mesoscale Meteorological Studies, University of Oklahoma, Norman, Oklahoma \\ R. Edwards, R. L. Thompson, J. A. Hart, and K. C. Crosbie \\ NOAA/Storm Prediction Center, Norman, Oklahoma
}

(Manuscript received 22 August 2005, in final form 31 January 2006)

\begin{abstract}
The notion of an "outbreak" of severe weather has been used for decades, but has never been formally defined. There are many different criteria by which outbreaks can be defined based on severe weather occurrence data, and there is not likely to be any compelling logic to choose any single criterion as ideal for all purposes. Therefore, a method has been developed that uses multiple variables and allows for considerable flexibility. The technique can be adapted easily to any project that needs to establish a ranking of weather events. The intended use involves isolating the most important tornado outbreak days, as well as important outbreak days of primarily nontornadic severe convective weather, during a period when the number of reports has been growing rapidly from nonmeteorological factors. The method is illustrated for both tornadic and primarily nontornadic severe weather event day cases. The impact of the secular trends in the data has been reduced by a simple detrending scheme. The effect of detrending is less important for the tornado outbreak cases and is illustrated by comparing rankings with and without detrending. It is shown that the resulting rankings are relatively resistant to secular trends in the data, as intended, and not strongly sensitive to the choices made in applying the method. The rankings are also consistent with subjective judgments of the relative importance of historical tornado outbreak cases.
\end{abstract}

\section{Introduction}

In developing synoptic climatology studies of weather events, it can be difficult to develop a method for ranking the significance of the chosen weather events. An example of the need for such a ranking is to choose the most important, prototypical cases for study. As part of an effort to understand the meteorological differences, if any, between days producing major tornado outbreaks from those that produce primarily nontornadic severe convective storms, we have been faced with just such a challenge. Part of the challenge is that there has never been any formal definition of a tornado outbreak. The American Meteorological Society's (AMS) Glossary of Meteorology (Glickman 2000; the Glossary hereafter) defines a tornado outbreak as

Corresponding author address: Dr. Charles A. Doswell III, Cooperative Institute for Mesoscale Meteorological Studies, University of Oklahoma, 120 David L. Boren Blvd., Suite 2100, Norman, OK 73072-7304.

E-mail: cdoswell@gcn.ou.edu "multiple tornado occurrences within a particular synoptic-scale system." This definition does not say how many tornadoes are required to constitute an outbreak, but the Glossary goes on to refer to Galway (1977), who defined an outbreak as comprising 10 or more tornadoes. Galway also states, "A tornado outbreak can mean many things to many people." The validity of Galway's statement is manifested in the many different uses to which the label "tornado outbreak" has been applied. Pautz (1969), for example, classified tornado outbreaks as small (6-10 tornadoes), moderate (11-20 tornadoes), and large (more than 20 tornadoes).

The term has been applied to what are obviously major events, such as the infamous 3 April 1974 "jumbo outbreak" (Fujita 1974) and also to local events with relatively few tornadoes (Blechman 1975; Zipser and Golden 1979). Van Tassel (1955) described a series of tornadoes from a single storm as an outbreak. Forbes and Wakimoto (1983) presented a case involving many tornadoes, as well as other severe convective events that they described collectively as an outbreak. Although Zipser and Golden (1979) referred to the three- 
tornado event they studied as an outbreak in the title of their paper, within the text they described it as a "minioutbreak." Numerous other examples of this diversity regarding the use of the term outbreak for severe convective events can be found. Furthermore, many other types of weather events have been described as outbreaks, notably cases with large numbers of severe weather reports (be they tornadic or not), or even incursions of cold air. Thus, not only is there no general agreement about the definition of a tornado outbreak, the word "outbreak" itself has been used in several different ways.

Our goal, however, is not to offer a formal definition for a severe weather outbreak. Individual projects focused on weather events that might be considered as outbreaks have specific circumstances and unique goals rendering pointless any attempt at creating a definition that would serve all possible goals equally well. Rather, we have developed herein a systematic way to rank weather events according to the specific requirements of any project.

We are engaged in a study of the environments in which major tornado outbreaks occur, with the goal of comparing them to the environments of primarily nontornadic severe storm outbreaks. Our objectives require that we focus on tornadoes and other severe convective storm events that develop in association with a particular synoptic system, consistent with the AMS Glossary definition given above. Studies of synopticscale environments from a number of cases have a long history. For example, Beebe (1956) developed what he called "tornado composite charts" by selecting cases involving three or more tornadoes. Although he did not use the term outbreak, his clear intention was to choose cases involving what he considered to be significant tornado events associated with strong synoptic-scale systems, rather than isolated tornado reports. Although three tornadoes seems like a small number in light of current tornado reporting standards, in the 1950s it could be considered at least a reasonable starting point for selecting cases. In developing a study of the environments associated with hurricane-induced tornadoes, McCaul (1991) applied a definition similar to that used by Pautz (1969).

An important consideration in ranking tornado outbreaks is their impact on society. Although it is possible for tornadoes to occur that have relatively little impact, it is generally the case that events including a relatively large number of powerful tornadoes are more likely to cause extensive damage and casualties than events with a small number of relatively weak tornadoes. This is a direct consequence of the correlation between intensity and path area (Brooks 2004); although not a one-to-one relationship, measures of societal impact are nevertheless useful in gauging the meteorological significance of a given event. Whereas any single measure of outbreak importance can be unrepresentative, it seems plausible to suggest that a combination of measures would be more likely to yield a robust ranking scheme. That is the direction we have pursued.

A major challenge for this task is the large secular growth in the number of tornado and severe thunderstorm reports that has primarily nonmeteorological origins (Brooks et al. 2003; Doswell et al. 2005). This growth makes it very difficult to compare the raw number of reported tornadoes for events separated by a decade or more (see Speheger et al. 2002). The growth of nontornadic severe thunderstorm reports has been even greater than the growth of tornado reports (Doswell et al. 2005). Any ranking based on the raw number of reports likely would be heavily biased toward the most recent events. Nevertheless, the number of tornadoes (or nontornadic severe thunderstorm reports) ought to have some influence on case selection.

One alternative is to estimate the trend in the number of reports and then remove it. This is the approach used by, for example, Doswell et al. (1993), Verbout et al. (2004), and Bruening et al. (2002). However, such an approach is simply focused on the number of events and we believe that multiple measures are needed. As first described in Edwards et al. (2004), we have developed a method for incorporating multiple variables describing a severe weather day in a systematic way to rank the case days. Note that these two approaches are not mutually exclusive; they can be combined and we have done so in this work.

That a single variable might not be adequate for producing a ranking of events has been recognized elsewhere. For example, when considering the El NiñoSouthern Oscillation (ENSO), Wolter and Timlin (1998) used the so-called multivariate ENSO index (MEI; more information available online at http:// www.cdc.noaa.gov/people/klaus.wolter/MEI/). Although the MEI formulation is very different in detail from what we are proposing as an outbreak ranking methodology, its intent is evidently to mitigate the vagaries associated with using a single variable.

In summary, our project requires us to develop a ranking scheme that has the following characteristics (in no particular order): 1) uses multiple variables to measure the meteorological and societal significance of a given outbreak day, 2) provides a reproducible result, 3) yields rankings reasonably consistent with what someone familiar with the history of such events would arrive at subjectively, at least for the highest-ranked cases, 4) accounts for the known large secular trends, 
TABLE 1. Basic information in the SPC database (Schaefer and Edwards 1999).

\begin{tabular}{ll}
\hline \hline \multicolumn{1}{c}{ Tornado reports } & \multicolumn{1}{c}{ Severe thunderstorm reports } \\
\hline Time of occurrence & Time of occurrence \\
Pathlength & Lat-lon \\
Path width & Type: hail, wind \\
Lat-lon of touchdown point & $\begin{array}{l}\text { Intensity: diameter of hail, speed } \\
\text { of wind (if available) }\end{array}$ \\
$\begin{array}{l}\text { Lat-lon of liftoff point } \\
\text { Fujita-scale rating }\end{array}$ & No. of fatalities \\
$\begin{array}{l}\text { No. of fatalities } \\
\text { No. of injuries }\end{array}$ & No. of injuries \\
Estimated damage cost & Estimated damage cost (since \\
(since 1998) & 1998 \\
\hline
\end{tabular}

and 5) results in rankings that are reasonably robust to any arbitrary parameter choices. For the purposes of the long-term project that has driven the effort to produce a ranking scheme, we need as clear a separation as possible between highly ranked tornado outbreaks and prototypical outbreaks of primarily nontornadic severe weather.

We develop the basic methodology for our ranking scheme in section 2. Section 3 presents the results of the scheme as applied to tornado outbreaks and documents the detrending scheme we used, and section 4 shows the results as used for primarily nontornadic severe convective storm outbreaks. Finally, section 5 offers a discussion of the results.

\section{The ranking scheme}

The database for the tornado and nontornadic severe thunderstorm reports that we are using is described in Schaefer and Edwards (1999). It includes information not only about the number of tornado and nontornadic severe thunderstorm reports for each day (which runs from 1200 UTC on the nominal date to 1159 UTC on the next), but also other variables that describe the reports and their impacts (Table 1 ). ${ }^{1}$ No outbreaks over multiple dates were considered; each outbreak day was considered separately.

From this information, it is possible to derive a set of variables that describe various aspects of each day's tornadoes (top row of Table 2) and nontornadic severe thunderstorms (top row of Table 3). These variables were selected subjectively as being pertinent in describing the significance of each case. They are discussed in detail in the sections to follow.

\footnotetext{
${ }^{1}$ Prior to 1998 , estimated damage costs were included in Storm Data, but only in the form of dollar amount categories that ranged over a full order of magnitude each (e.g., from $\$ 5000$ to $\$ 50,000$; J. T. Schaefer 2005, personal communication). As a result, we chose not to use the damage cost estimates as a variable in the scheme.
}

Given a set of variables $x_{1}, x_{2}, \ldots, x_{n}$, then for each date in the database, we have values for these $n$ variables $x_{1}^{(1)}, x_{1}^{(2)}, \ldots, x_{1}^{(m)} ; x_{2}^{(1)}, x_{2}^{(2)}, \ldots, x_{2}^{(m)} ; x_{n}^{(1)}, x_{n}^{(2)}, \ldots$, $x_{n}^{(m)}$, where $m$ is the number of dates available. Generally speaking, these variables have very different means and variances, so it is useful to standardize them, according to the conventional statistical technique

$$
\tilde{x}_{i}^{(j)}=\frac{x_{i}^{(j)}-\mu_{i}}{\sigma_{i}},
$$

where

$$
\mu_{i}=\frac{1}{m} \sum_{j=1}^{m} x_{i}^{(j)}
$$

and

$$
\sigma_{i}=\left\{\frac{1}{m-1} \sum_{j=1}^{m}\left[x_{i}^{(j)}-\mu_{i}\right]^{2}\right\}^{1 / 2}
$$

are the means and standard deviations, respectively, for the variables. This converts all variables to standard normal form, ${ }^{2}$ with zero mean and a standard deviation of unity. Thus, it becomes possible to form a linear weighted average of all the variables, that is, an index $I$ for each date in the database, according to

$$
I^{(j)}=\frac{\sum_{i=1}^{n} w_{i} \tilde{x}_{i}^{(j)}}{\sum_{i=1}^{n} w_{i}},
$$

where the weighting allows us the flexibility to put greater or lesser emphasis on particular parameters. This formulation of the index allows us to choose the magnitude of the weight values arbitrarily, because it is normalized by the sum of the weights, in a way similar to simple diagnostic objective analysis techniques. For our purposes, it was straightforward to choose weights with values in the range $(-5,+10)$. By this method, the relative weight values are what matters. This will be illustrated in the following two sections.

\section{Tornado outbreak day rankings}

For each date, we considered the number of tornadoes of any F-scale rating on that day, the number of violent (F4 and F5 rating) tornadoes, the number of significant tornadoes ( $\geq \mathrm{F} 2$ rating), the destruction potential index (DPI) developed by Thompson and Vescio (1998; see the explanation below), the total

\footnotetext{
${ }^{2}$ This terminology (standard normal form) does not require or imply that the variable is normally distributed about the mean, however.
} 
TABLE 2. Variables used for the ranking of tornado outbreak days for the period 1970-2003. An explanation of this table is provided in section 3 .

\begin{tabular}{|c|c|c|c|c|c|c|c|c|}
\hline & $\begin{array}{l}\text { No. } \\
\text { tornadoes* }\end{array}$ & $\begin{array}{l}\text { No. violent } \\
\text { tornadoes* }\end{array}$ & $\begin{array}{c}\text { No. significant } \\
\text { tornadoes* }\end{array}$ & DPI & Pathlength & No. deaths & $\begin{array}{l}\text { No. killer } \\
\text { tornadoes }\end{array}$ & $\begin{array}{l}\text { No. } 80-\mathrm{km} \\
\text { tracks* }\end{array}$ \\
\hline Mean & 0.85 & 0.94 & 0.82 & 25.7 & 53.2 & 1.53 & 0.42 & 0.95 \\
\hline Std dev & 0.61 & 4.65 & 1.28 & 103.0 & 102.1 & 9.90 & 1.58 & 4.45 \\
\hline Wt $U$ & 1 & 4 & 8 & 7 & 10 & 2 & 5 & 4 \\
\hline Wt N1 & 1 & 4 & 8 & 7 & 10 & 2 & 5 & 4 \\
\hline Wt N2 & 6 & 6 & 10 & 7 & 8 & 1 & 5 & 4 \\
\hline
\end{tabular}

* Detrended.

pathlength of all tornadoes, the number of fatalities, the number of killer tornadoes, and the number of tornadoes with track lengths $\geq 80 \mathrm{~km}$. Although relevant to ranking tornado days, this set of variables is somewhat arbitrary. We cannot assert that they are optimal in any sense, but it is not clear that optimality must be demonstrated for this purpose. We argue a posteriori that our final rankings are consistent with what many severe storm meteorologists would agree are the important cases during the period. However, we certainly do not claim that our final rankings are the only ones possible, nor is ours the only method by which such rankings can be done.

\section{a. The DPI}

The DPI (Thompson and Vescio 1998) has not been presented heretofore in the refereed literature. It is defined by

$$
\mathrm{DPI}=\sum_{i=1}^{n} a_{i}\left(F_{i}+1\right)
$$

where $n$ is the number of tornadoes on that day, $a_{i}$ is a measure of the tornado damage area (pathlength multiplied by path width) for each tornado, and $F_{i}$ is the Fujita-scale rating (F0-F5) for each tornado. Adding unity to the F-scale rating is done so that an F0 rating yields a nonzero value. This represents a nonlinear combination of the pathlength and width with the
F-scale rating. The DPI clearly puts the greatest emphasis on large, violent, long-track tornadoes, which are the most likely to cause large amounts of damage, hence, its name. Note that the DPI is far from independent of some of the other variables used in our scheme. The fact that it is a nonlinear combination of the variables means it can contain independent information when used in this linear weighting scheme. It is evident that the variables in our scheme are likely to be correlated, so the scheme has not been optimized in a statistical sense. Nevertheless, it succeeds for our purposes and can be adapted readily to other purposes.

\section{b. Implementation of the ranking scheme}

Using the database for the period 1970-2003, the relevant variables for each date during the period were collected. For a starting point, only days with seven or more tornadoes were considered. This is not a large number of tornadoes on a single day, but this choice was made because it was felt that no day with fewer tornadoes than seven would be likely to be called an outbreak in any era during the period $1970-2003 .{ }^{3}$ Note that a little more than half the dates in the period-a

\footnotetext{
${ }^{3}$ As will be evident in the rankings presented below, the choice of seven tornadoes as the cutoff for consideration has absolutely no impact on those rankings for the top- 20 or even the top-50 cases, all of which involved far more than seven tornadoes.
}

TABLE 3. Variables used for the ranking of nontornadic severe weather outbreak days. Terms are described in detail in section 4 , including an explanation of the meaning of the middle $50 \%$ area parameter, which was used differently from the others in the calculation of an index value.

\begin{tabular}{lccccccc}
\hline \hline & No. severe* & No. tornadoes* & No. wind* & $\begin{array}{c}\text { No. significant } \\
\text { wind* }\end{array}$ & No. hail* & $\begin{array}{c}\text { No. significant } \\
\text { hail* }\end{array}$ & $\begin{array}{c}\text { Middle } 50 \% \\
\text { area }\end{array}$ \\
\hline Mean & 0.86 & 0.27 & 1.00 & 0.94 & 0.82 & 0.73 & 31.7 \\
Std dev & 0.27 & 0.14 & 0.50 & 1.20 & 0.53 & 0.82 & 35.5 \\
Wt N1 & 8 & -5 & 7 & 4 & 7 & 4 & - \\
Wt N2 & 8 & -5 & 4 & 7 & 4 & 7 & - \\
\hline
\end{tabular}

* Detrended. 
TABLE 4. Illustration of several very differerent top-20 rankings (descending order) for tornado days during the period 1970-2003, using different single variables. The dates 3 April 1974, 4 May 2003, and 27 May 1973 are in boldface to illustrate the variability in the rankings (see text).

\begin{tabular}{|c|c|c|c|c|}
\hline No. tornadoes & No. significant tornadoes & No. violent tornadoes & No. deaths & DPI \\
\hline 3 Apr 1974 & 3 Apr 1974 & 3 Apr 1974 & 3 Apr 1974 & 3 Apr 1974 \\
\hline 24 Jun 2003 & 16 Jun 1992 & 2 Jun 1990 & 21 Feb 1971 & 27 Mar 1994 \\
\hline 4 May 2003 & 2 Jun 1990 & 1 Mar 1997 & 31 May 1985 & 31 May 1985 \\
\hline 21 Jan 1999 & 2 Apr 1982 & 31 May 1985 & 28 Mar 1984 & 28 Mar 1984 \\
\hline 18 May 1995 & 26 Apr 1991 & 28 Mar 1984 & 10 Apr 1979 & 21 Nov 1992 \\
\hline 6 May 2003 & 7 Jun 1984 & 26 Apr 1991 & 3 May 1999 & 17 Apr 1970 \\
\hline 19 Apr 1996 & 13 Mar 1990 & 2 Apr 1982 & 8 Apr 1998 & 13 Mar 1990 \\
\hline 3 May 1999 & 1 Mar 1997 & $13 \operatorname{Mar} 1990$ & 22 Feb 1998 & 26 Apr 1991 \\
\hline 10 Nov 2002 & 4 May 2003 & 4 May 2003 & 27 Mar 1994 & 3 May 1999 \\
\hline 2 Jun 1990 & 21 Jan 1999 & 3 May 1999 & 4 May 2003 & 7 May 1993 \\
\hline 26 Apr 1994 & 10 Nov 2002 & 17 Apr 1970 & 10 Nov 2002 & 27 May 1973 \\
\hline 16 Jun 1992 & 22 Nov 1992 & 21 Nov 1992 & 2 Apr 1982 & 22 Nov 1992 \\
\hline 2 Apr 1982 & 27 May 1973 & 20 Mar 1976 & 28 Aug 1990 & 8 Apr 1999 \\
\hline 10 May 2003 & 20 Mar 1976 & 21 Nov 1992 & 27 May 1997 & 8 Jun 1985 \\
\hline 13 Mar 1990 & 21 Nov 1992 & 8 Apr 1999 & 11 May 1970 & 1 Mar 1997 \\
\hline 15 Jun 1992 & 7 Apr 1980 & 4 May 1977 & 1 Mar 1997 & 8 Jun 1974 \\
\hline 8 May 1988 & 19 Apr 1996 & 26 Mar 1976 & 4 Apr 1977 & 20 Mar 1976 \\
\hline 8 Jun 1993 & 31 May 1985 & 5 May 1989 & 26 Apr 1991 & 29 Mar 1976 \\
\hline 26 Apr 1991 & 18 May 1995 & 21 Feb 1971 & 17 Apr 1970 & 2 Jun 1990 \\
\hline 8 Apr 1999 & 8 Jun 1974 & 8 Jun 1995 & 8 Jun 1974 & 2 Apr 1982 \\
\hline
\end{tabular}

total of 6330 out of 12418 , or $51 \%$ - are days on which no tornadoes were reported and so were not considered at all. During the period, there were 1447 days with seven or more reported tornadoes (nearly $12 \%$ ), an average of about 42 such days per year.

If we only consider a single variable, such as the number of reported tornadoes, the effect of secular trends is manifested in the predominance of certain dates (most recent dates, for the number of tornadoes; older dates for the number of fatalities). In general, there is considerable disparity between rankings according to different variables, as illustrated in Table 4 . That the rankings would be so sensitive to the variable chosen was anticipated. When using any single variable, it would be difficult to justify the choice of cases, as proponents in favor of a particular variable for the ranking would be inclined to argue with any other choice. With the lone exception of 3 April 1974, which by any standard is the greatest single-day outbreak of tornadoes in the period, the rankings shown in Table 4 are very different rankings. For example, 27 May 1973 only shows up in two of the five rankings, while 4 May 2003 is absent from only one, but its relative position varies considerably. Thus, a different approach is needed.

A critical issue in the larger study that prompted this work is the relationship between tornadoes and a particular synoptic-scale weather system. As Galway (1977) pointed out, it is possible to achieve a particular threshold tornado count by having a scattering of tornadoes about the whole country, whereas what we wished to consider an outbreak would be dominated by events associated with a particular synoptic-scale system. Thus, most of the tornadoes on an outbreak day should be clustered spatially or closely aligned, rather than scattered. We wanted to avoid considering days when the tornadoes are widely dispersed. As it turned out, this was not a problem for all the top-ranked tornado outbreak cases. However, as shown below, it was a definite problem for some cases involving outbreaks of primarily nontornadic severe weather.

The variables used for ranking tornado days and shown in Table 2 include the following:

- The "No. tornadoes" is the number of tornadoes on that day. It is weighted the least of all the variables, reflecting the perceived negative impact of the secular trend in tornado reporting. However, in one of the weighting schemes for the detrended data (see below) it was given substantially higher weight.

- The "No. violent" is the number of F4- and F5-rated tornadoes on that day. Although many important outbreaks produce at least two violent tornadoes, the rating of tornado intensity can be highly dependent on what the tornadoes actually hit. Further, there is likely to be some reluctance to give tornadoes such a high rating if it is not clear that the structures hit were capable of wind resistance consistent with the highest F-scale ratings. Thus, this variable is given only moderate weighting.

- The "No. significant tornadoes" is the number of tor- 
TABLE 5. Ranking and associated $O$-index values for the top-20 tornado outbreaks during the period 1970-2003 (denoted T7003) using (column 1) the raw values of the variables and the "weight $U$ " weighting of the variables for the (column 2) $O$ index; (column 3 ) the detrended variables with the "weight N1" weighting (which is the same as weight $U$ ) and the associated (column 4) $O$-index values; and (column 5) the detrended variables with the "weight N2" weighting and the associated (column 6) $O$-index values. See Table 2 for the weights. Odd-numbered years are in boldface to facilitate comparison of the rankings.

\begin{tabular}{|c|c|c|c|c|c|}
\hline T7003-U & $O$ index & T7003-N1 & $O$-index N1 & T7003-N2 & $O$-index N2 \\
\hline 3 Apr 1974 & 21.073 & 3 Apr 1974 & 22.565 & 3 Apr 1974 & 21.679 \\
\hline 31 May 1985 & 5.328 & 31 May 1985 & 6.063 & 31 May 1985 & 5.556 \\
\hline 13 Mar 1990 & 4.562 & 13 Mar 1990 & 5.154 & 13 Mar 1990 & 5.028 \\
\hline 13 Mar 1990 & 4.474 & 4 Мау 2003 & 4.974 & 4 May 2003 & 4.962 \\
\hline 21 Nov 1992 & 4.184 & 13 Mar 1990 & 4.938 & 2 Jun 1990 & 4.699 \\
\hline 2 Apr 1982 & 4.072 & 21 Nov 1992 & 4.700 & 10 Nov 2002 & 4.697 \\
\hline 4 May 2003 & 3.999 & 26 Apr 1991 & 4.644 & 26 Apr 1991 & 4.683 \\
\hline 26 Apr 1991 & 3.957 & 22 Nov 1992 & 4.548 & 21 Nov 1992 & 4.439 \\
\hline 22 Nov 1992 & 3.942 & 28 Mar 1984 & 4.494 & 22 Nov 1992 & 4.392 \\
\hline 27 May 1973 & 3.941 & 2 Jun 1990 & 4.396 & 2 Apr 1982 & 4.382 \\
\hline 28 Mar 1984 & 3.820 & 2 Apr 1982 & 4.203 & $28 \operatorname{Mar} 1984$ & 4.247 \\
\hline 27 Mar 1994 & 3.773 & 8 Apr 1999 & 4.058 & 1 Mar 1997 & 4.068 \\
\hline 2 Jun 1990 & 3.558 & 27 Mar 1994 & 4.046 & 8 Apr 1999 & 3.932 \\
\hline 7 Jun 1984 & 3.312 & 1 Mar 1997 & 3.867 & 3 May 1999 & 3.623 \\
\hline 8 Apr 1999 & 3.231 & 27 Мау 1973 & 3.650 & 27 Mar 1994 & 3.585 \\
\hline 17 Apr 1970 & 3.090 & 3 Мау 1999 & 3.510 & 27 Мау 1973 & 3.528 \\
\hline 21 Feb 1971 & 3.052 & 7 Jun 1984 & 3.460 & 21 Jan 1999 & 3.431 \\
\hline 21 Feb 1999 & 3.023 & 21 Jan 1999 & 3.278 & 7 Jun 1984 & 3.417 \\
\hline 20 Mar 1976 & 2.994 & 17 Apr 1970 & 3.118 & 20 Mar 1976 & 3.236 \\
\hline 3 Мay 1999 & 2.929 & 20 Mar 1976 & 3.010 & 16 Jun 1992 & 2.768 \\
\hline
\end{tabular}

nadoes rated $\mathrm{F} 2$ or higher. It is accorded a relatively high weight in all cases because most tornadoes with high impact (in terms of damage and/or casualties) are rated $\mathrm{F} 2$ and higher.

- The "Pathlength" is in kilometers, and represents the cumulative pathlength of all the tornadoes on that day. This receives the highest weighting in two of the weighting choices, because it is strongly associated with high damage potential and its values are known with relatively high accuracy and precision.

- The "DPI" was weighted relatively highly because of its value in describing the threat associated with the tornadoes on that date. However, it is not known with the same degree of confidence as total pathlength and, because of some overlap between DPI and total pathlength, the DPI gets a lower relative weighting than the total pathlength.

- The "No. deaths" is the total fatalities for the day. It received a relatively low weight in all rankings because fatalities are the result of the more or less random concatenation of tornadoes with humans. A particular case can have only a few deaths and still be a meteorologically significant day, whereas a large number of fatalities can result from a single tornado (such as the Plainfield tornado of 1990) that by itself would not constitute an outbreak. Even though the number of fatalities is known with fairly high accuracy, it is strongly influenced by nonmeteorological factors.
- The "No. killers" is the number of tornadoes that produced one or more fatalities. Although like the total fatalities, this can vary widely from nonmeteorological factors, an event that results in a large number of killer tornadoes is likely to result from a spatially widespread group of significant tornadoes. The moderate weighting reflects the uncertainty of this variable.

- The "No. 80-km tracks" is the number of tornadoes on that day that had track lengths $80 \mathrm{~km}$ or more in length. It is related to the total pathlength for the day. An outbreak with a large number of long-track tornadoes is likely to be a significant event. However, its large correlation with total pathlength affords it a smaller relative weight than given to the total pathlength.

Using these variables and the relative weightings shown in Table 2, we produced a final top-20 ranking for the period 1970-2003 (Table 5, column 1). The socalled $O$ index is named for outbreaks of tornadoes and uses the particular variables with the weightings in Table 2 in Eq. (4). The "jumbo outbreak" of 1974 (Fujita 1974) stands way above all the rest, consistent with any reasonable knowledge of tornado outbreak history. That outbreak is, by any measure, the most important single outbreak during the period and perhaps in the recorded history of tornadoes in the United States. 


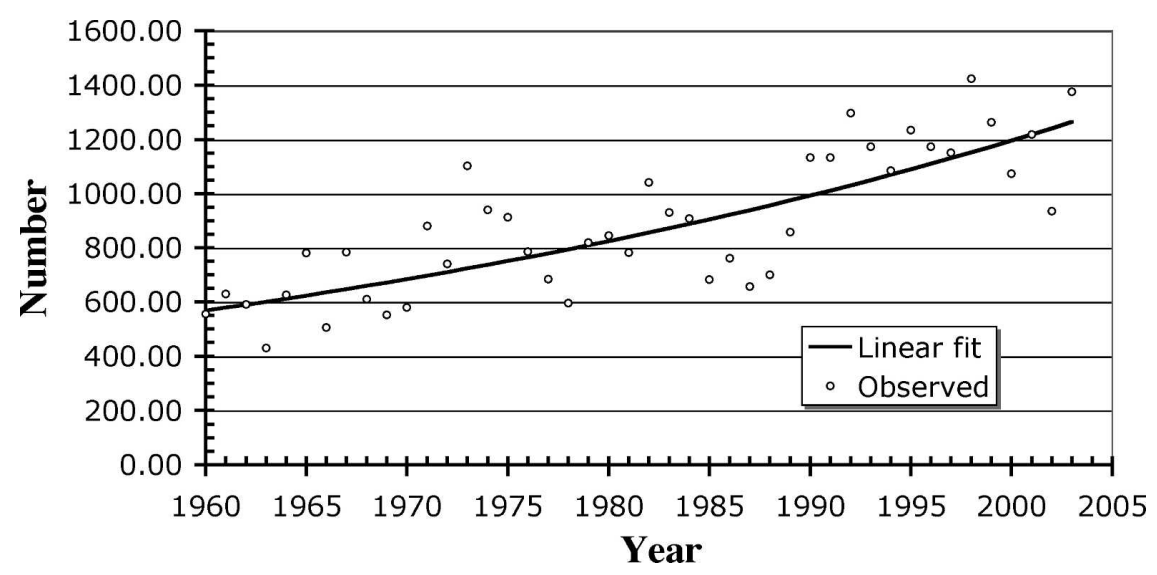

FIG. 1. The regression line (solid line) is fit to the logarithm of the total number of tornado reports per year (open circles) and then plotted on a linear scale, resulting in a nonlinear trend line.

\section{c. Detrending the tornado variables}

The alternative rankings presented in Table 5 represent the results of using our method after having detrended those variables found to exhibit a marked trend through the period. We used a method similar to that developed by Verbout et al. (2004), in that it accounts for the long-term trends in the data. Figure 1 illustrates the nature of the problem, revealing that the number of reported tornadoes has roughly doubled during the period 1960-2003. The regression line shown on the figure was done with a simple linear fit to the logarithm of the number of tornado reports, which gives a nonlinear trend line when plotted on a linear scale. However, it was felt that this trend line is unsuitable for detrending the daily number of tornado reports (or any of the other variables). If this line were used, it would be necessary to convert it to a daily value by dividing by 365 (the number of days in a year), which would be unrealistically low for the days we would be considering (days with seven or more reported tornadoes). Hence, we used a similar process to fit a regression line to the sum of the reported tornadoes on the top 30 days $^{4}$ of each year (according to the number of reported tornadoes), resulting in Fig. 2. The total number of tornado reports in the top 30 days of the year is slightly less than half of the total for the whole year in most years, although this fraction has some modest interannual variation (not shown). To convert to a daily average value, the value from the regression line for a given year is divided by 30 .

A detrended variable on a given date is derived by

\footnotetext{
${ }^{4}$ Recall that only days with seven or more tornadoes were considered, and that during the period 1970-2003, there was an average of 42 such days per year.
}

dividing the reported value for a given date by the daily average for that particular year. The detrended variables are greater than unity if the variable (such as the number of reported tornadoes) on that day exceeds the daily average value of that variable for that year, and less than unity if the number is less than that daily average value. These detrended values are then converted to standard normal variables in the same way as the raw values were. Because we had data for all the variables going back to 1960 for tornado days, we used trend lines fitted to that extended period of record, even though values for the years 1960-69 were not used in this ranking for the period 1970-2003.

It was found that meaningful trends are not present in all the variables. As an example, Fig. 3 shows that no obvious trend was present in the DPI values. A slight downward trend with time can be seen, but this is not strong enough to be considered significant, given the interannual variability, and does not justify the detrending effort. Of the variables used, only four were found to have sufficiently clear trends to warrant the detrending process: the number of all tornadoes, the number of significant tornadoes, the number of violent tornadoes, and the number of tornadoes with track lengths $\geq 80 \mathrm{~km}$. Curiously, the trends in all but the number of all tornadoes were downward with time. This might be related to some reporting biases mentioned by Verbout et al. (2004).

\section{Primarily nontornadic severe storm outbreak day rankings}

\section{a. Implementation of the ranking scheme}

For each day, we considered the total number of severe storm reports, the number of tornadoes, the num- 


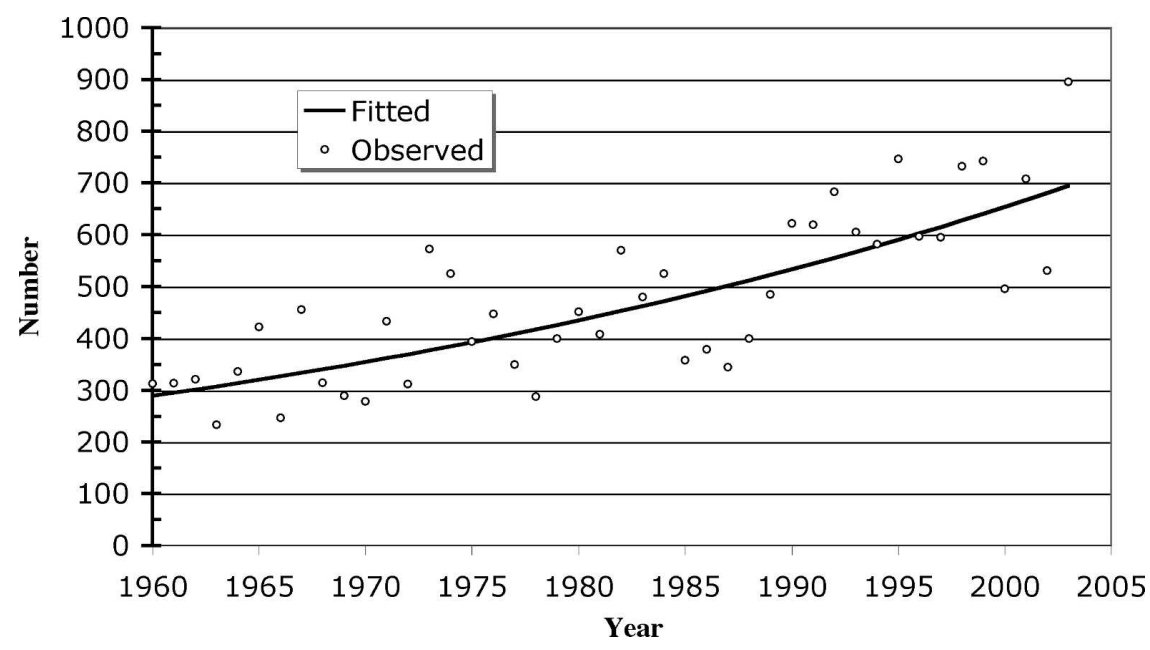

FIG. 2. Similar to Fig. 1 but for the total number of tornado reports on the top 30 days of each year.

ber of wind reports, the number of hail reports, the number of significant wind reports [winds measured $\left.\geq 65 \mathrm{kt}\left(33 \mathrm{~m} \mathrm{~s}^{-1}\right)\right]$, and the number of significant hail reports [hailstone diameters $\geq 2$ in. $(5 \mathrm{~cm})]$. Our goal within the context of the larger study that motivated this ranking effort was to find days on which the primary mode of severe convective weather was not tornadoes.

For days with essentially nontornadic severe convective storms, candidate variables were selected in a rather different way from the selection of tornado outbreak candidates. For these primarily nontornadic events, the period of record was different: 1980-2003, in part because of the lack of information about the daily totals of significant severe reports in the Storm Prediction Center (SPC) database before 1980. Furthermore, major tornado outbreaks are generally less frequent than major outbreaks of primarily nontornadic severe convective storms, so a shorter period is acceptable to find an appropriate sample size for primarily nontornadic severe storm outbreak days. For each year, the days were sorted according to the total number of severe reports of any kind, including tornadoes. Out of the top 30 days (according to the number of reports) for

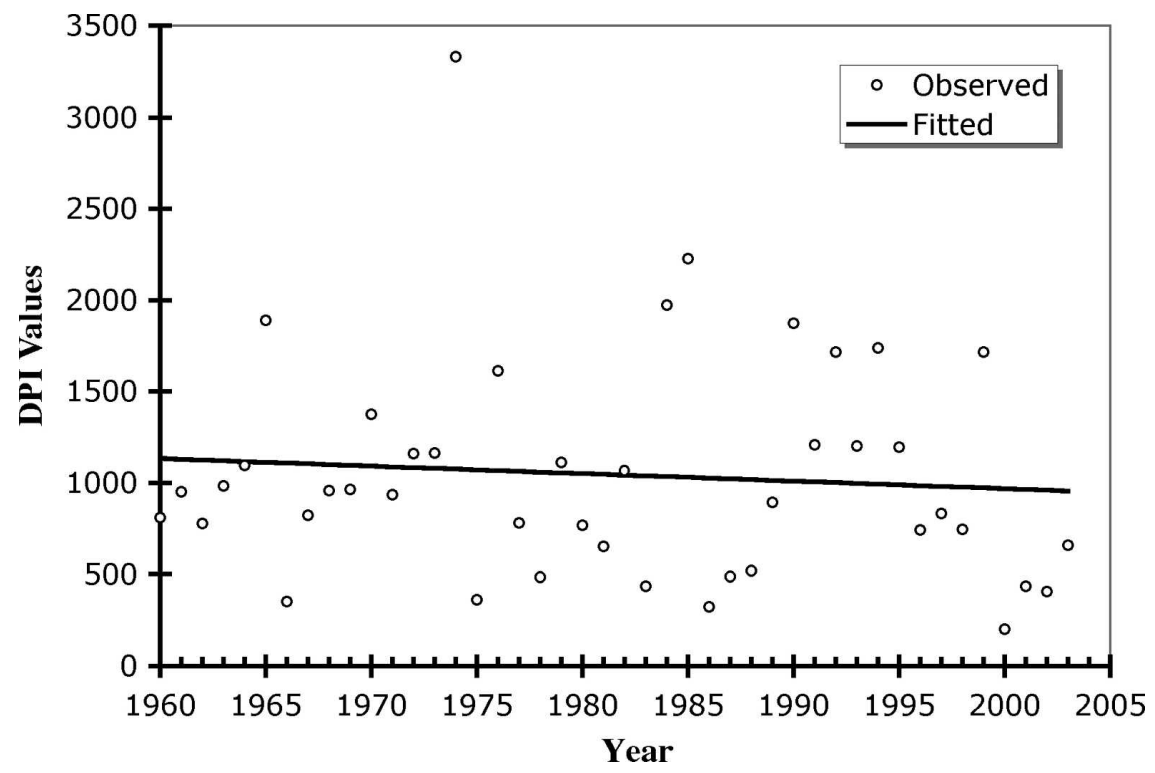

FIG. 3. Similar to Fig. 1 but for DPI values. 


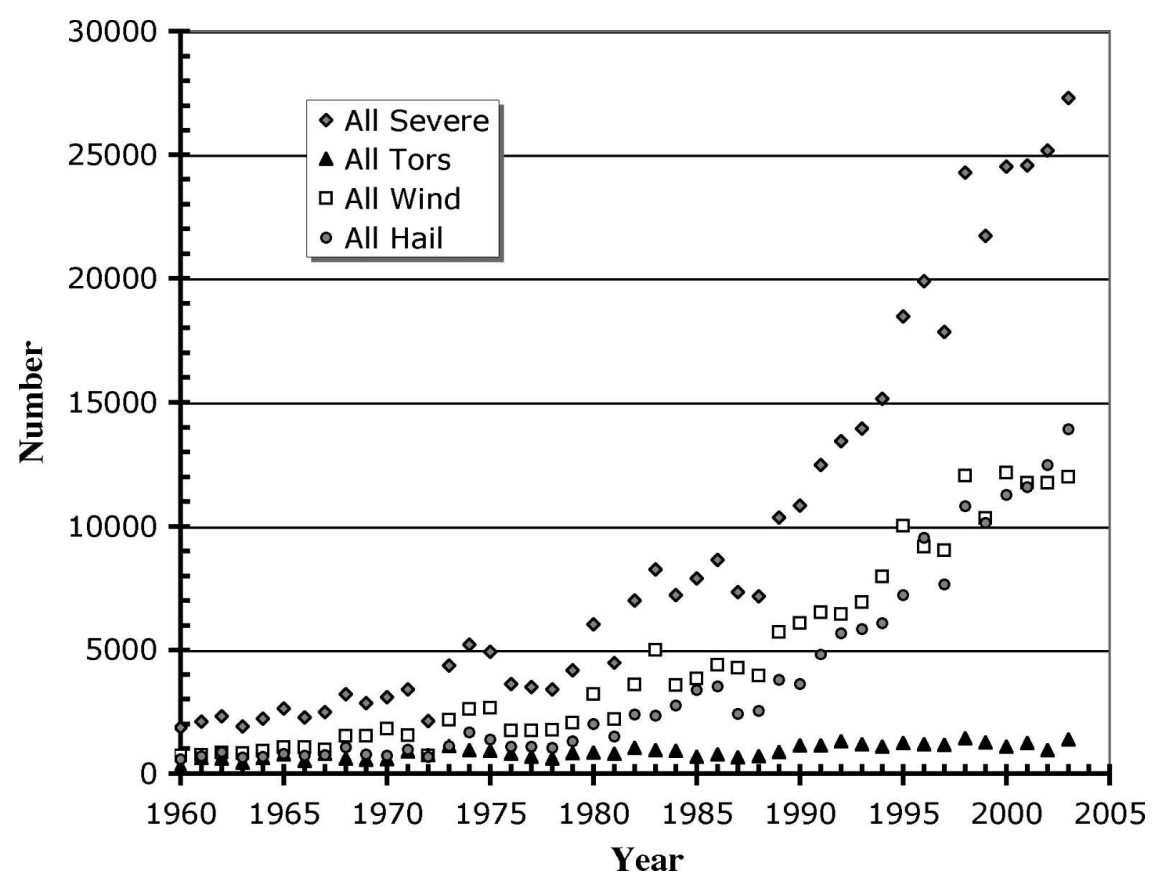

FIG. 4. Trends in reporting of severe weather, 1960-2003.

each year, only days with six or fewer tornadoes were chosen as candidates for consideration in the rankings. ${ }^{5}$ It was decided early in the effort that a few tornadoes were acceptable on such days, but they should not be more than a small fraction of the total number of reports, and no date that was considered a candidate for a tornado outbreak by the standards developed in the previous section would be used; these two sets of event days are designed to be mutually exclusive. That is, days with six or fewer tornadoes were automatically excluded from the set of candidate dates even considered for ranking of major tornado outbreaks.

The variables considered (Table 3 ) are selfexplanatory. The number of fatalities and/or injuries on any given day dominated by nontornadic severe convection is sufficiently small (usually zero on the vast majority of days) that including such variables was not considered to be of much value in the rankings.

\section{b. Detrending}

The very large secular trends in the data caused us to decide that, unlike the ranking of tornado outbreaks, no method of ranking primarily nontornadic severe storm days could even be attempted without first detrending the data. The trends in nontornadic severe

\footnotetext{
${ }^{5}$ As with the tornado outbreaks, the final rankings are relatively insensitive to this choice, for similar reasons.
}

storm reports are discussed in Doswell et al. (2005) and illustrated in dramatic fashion by Fig. 4. Note the difference in the magnitude of the trends in nontornadic severe reports compared with that for tornadoes, the latter of which is barely evident at this scale.

Essentially the same detrending technique was applied as that used for tornado outbreaks. The variables were detrended by dividing each event's date by the average daily value of that variable for that particular year, derived from the regression line fitted to the logarithm of the variable for the top 30 days (according to the number of all severe reports) of each year. An example of this fitted regression line is shown in Fig. 5. Again, the detrended values of the variables were converted to standard normal variables before use in the calculation of the $S$ (for severe storms outbreak) index.

\section{c. The middle $50 \%$ parameter}

For the outbreaks of primarily nontornadic severe storms, the relationship of the reports to the synoptic system proved to be a much more challenging aspect of the ranking. Unlike tornado outbreaks, large numbers of essentially nontornadic severe convective storm reports did not have such a marked tendency for geographical clustering. On many dates with a large number of nontornadic severe storm reports, the reports were rather widely dispersed, instead of being closely associated with some synoptic-scale system. On other dates, there would be a cluster of reports tied to a syn- 


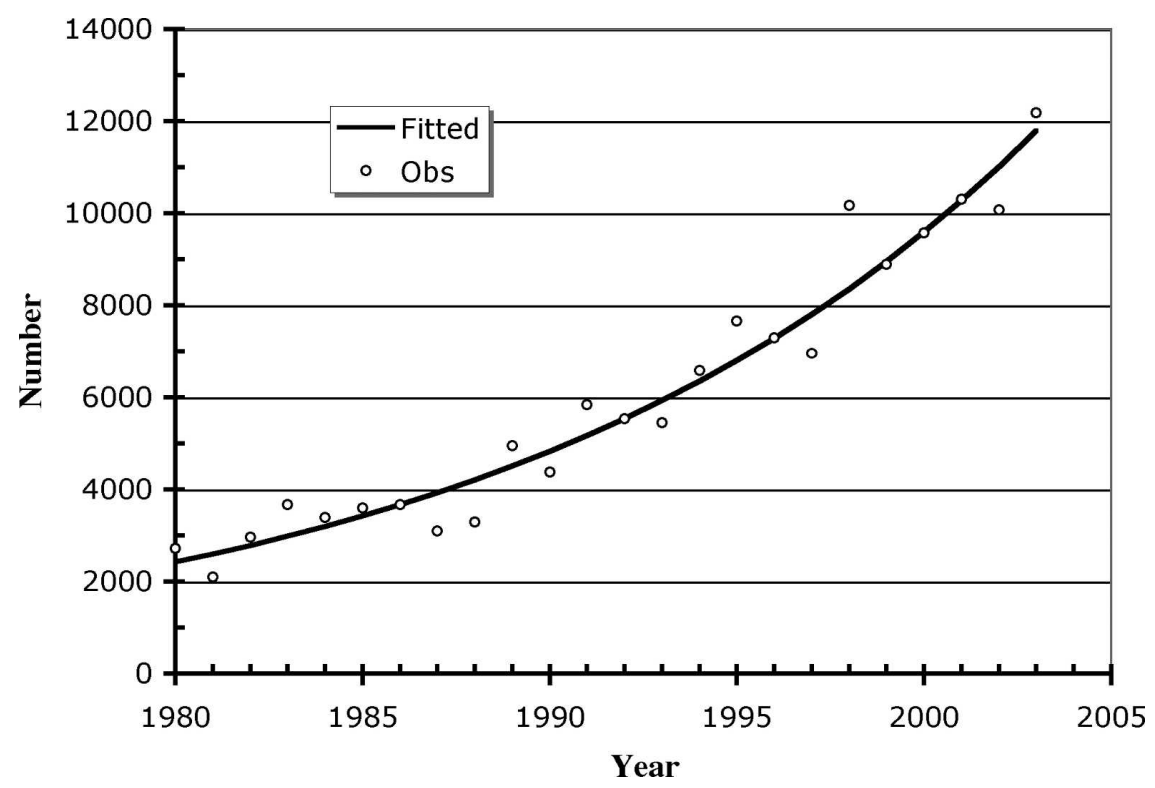

FIG. 5. Similar to Fig. 2 but for all severe reports on the top 30 days in a year.

optic-scale system, but they might be only a small fraction of the otherwise widely scattered reports and, by themselves, would not constitute an event that could be considered an outbreak. Figure 6 illustrates some examples of problem days.

To account for this, after developing the $S$-index rating (in a way comparable to that for the $O$ index) on a preliminary basis (recall Table 3), distributions of the latitude and longitude of severe storm report locations were constructed for each convective day. The largest and smallest $25 \%$ of latitude and longitude locations of the reports are removed from the distribution, leaving a range of values for half of the day's reports centered on the median latitude and longitude. ${ }^{6}$ The area (in square degrees of latitude-longitude) covered by this middle $50 \%$ of the reports is calculated as a measure of clustering, where a smaller area infers a more concentrated cluster of reports. Finally, the middle $50 \%$ area (lengths measured in degrees latitude and longitude) is converted to a unit-normal variable that scales to the order of the initial $S$ index. Subtraction of this normalized area term from the preliminary $S$ index results in the greatest $S$-index reduction when reports are scattered over a large geographic area, and the least $S$-index re-

\footnotetext{
${ }^{6}$ This method can have some difficulty with the occasional case where the reports are concentrated into two (or more) spatially distinct clusters (e.g., Fig. 6a). Plans are to develop more complex methods to account for this possibility, but the number of cases where this was an issue was generally small and this simple scheme worked well enough.
}

duction when the majority of reports are concentrated in a single cluster. This simple scheme appears to have solved the problem of widely scattered nontornadic severe storm reports.

\section{d. Results of the ranking}

Using this method, we produced rankings of primarily nontornadic severe convective storm outbreak days (Table 6). The two different weighting schemes (see Table 3) are similar except for reversing the emphasis on significant hail and wind reports versus all hail and wind reports. The small shift in the ranking suggests that this is not a major issue in the ranking, as the order is only moderately sensitive to this change.

\section{Summary and discussion}

The ranking of weather events can be rather controversial, for several reasons. There can be a large difference between the meteorological significance of a weather event and its societal impact. Not all events having a large societal impact are particularly noteworthy in terms of the meteorology, whereas not all major meteorological events occur in locations where they affect humans. This is especially true for severe convective storms because they generally cover only a small area during the course of a single day; their interaction with humans is unlikely on any day and becomes important more or less randomly, and infrequently. Despite this, it is clear that meteorological and societal 

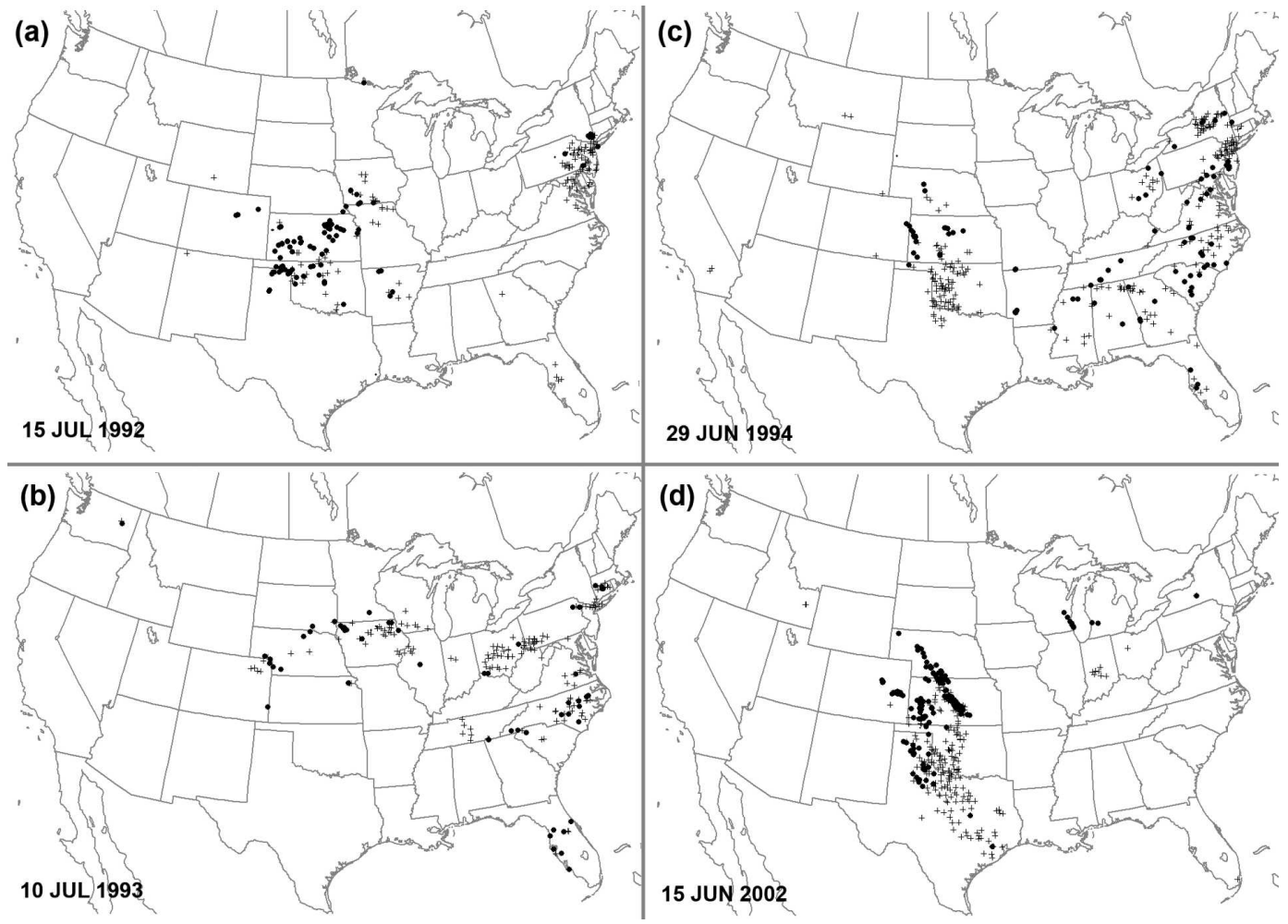

FIG. 6. Examples of the kinds of report distributions that can occur on days with a large number of nontornadic severe reports: (a) separated distinct clusters of reports, (b) widely dispersed reports, (c) mixed modes of reports, and (d) cluster with numerous outliers. Severe wind events are denoted with a plus sign and severe hail events with a gray filled circle.

significance are far from mutually exclusive. Thus, our scheme melded both meteorological and societal impact variables for tornado outbreaks. Even if it is felt that only the meteorological significance of an event is relevant in the ranking, however, deciding what quantitative aspects of the event to consider can be challenging. For example, is a large number of tornadoes on a given day more or less important than the occurrence of a few high-intensity tornadoes? The solution to this dilemma is to develop a multivariate index.

The existence of nonmeteorological secular trends in the severe storm report data complicates this task considerably. We have shown this to be even more important for the nontornadic severe storms than for tornadoes, in general. Our detrending scheme fits a regression line to the logarithm of the variable being detrended, thereby allowing for a nonlinear trend, which many of the variables seem to exhibit. We have accounted, at least in part, for these substantial secular trends in the reporting of severe storms and our method appears to be relatively insensitive to the subjective choices we made. Other possible techniques exist, but our ranking does not appear to suffer from "temporal myopia" whereby the most recent events are generally ranked the highest owing to secular trends in the data.

Because our goal was to pick a large sample of important weather events from the severe storm report database as cases for inclusion in a synoptic climatology, our proposed methodology has proven to be a reasonably robust way to do so. Furthermore, it can be adapted easily to other types of weather events, such as winter storms or flash floods. For other weather events, it may or may not be desirable for the resulting rankings to be reasonably consistent with the subjective experience of those familiar with the history of such events. In the case of tornado outbreaks, we believe it was useful to use our subjective knowledge of tornado outbreaks to develop a reproducible scheme that would be consistent with our perceived relative importance of historical tornado outbreak days. On the other hand, because we were not familiar with the history of primarily nontornadic severe thunderstorm event days, subjective knowledge played no role in the development of an index for ranking such days. For the essentially nontornadic severe storm outbreak days, it would be useful to know precisely how older cases would look 
TABLE 6. Two different rankings on the top-20 days with primarily nontornadic severe weather. See Table 3 for the weightings. Note the similarity, notably at the top of the table, between the two rankings- two dates are in boldface, 6 May 1986 and 20 June 1997, to illustrate the moderate amount of shuffling in the rankings.

\begin{tabular}{cccc}
\hline \hline 8003-N1 & $S$ index & 8003-N2 & $S$ index \\
\hline 19 Jul 1983 & 4.17 & 19 Jul 1983 & 4.18 \\
8 Jun 1982 & 3.06 & 8 Jun 1982 & 3.20 \\
7 Jun 1985 & 2.52 & 7 Jun 1985 & 2.45 \\
2 May 2003 & 2.26 & 2 May 2003 & 2.30 \\
6 May 1986 & 1.89 & 20 Jun 1997 & 2.07 \\
21 May 1989 & 1.78 & 21 May 1989 & 1.90 \\
20 Jun 1997 & 1.69 & 6 Aug 1980 & 1.76 \\
24 Jun 1985 & 1.55 & 24 Jun 1985 & 1.60 \\
10 Jul 1985 & 1.43 & 4 Jul 1992 & 1.52 \\
6 Aug 1980 & 1.38 & 20 Nov 1989 & 1.4 \\
5 Jun 1985 & 1.36 & 6 May 1986 & 1.40 \\
4 Jul 1985 & 1.35 & 2 Jul 1980 & 1.33 \\
20 Nov 1989 & 1.309 & 8 May 1981 & 1.32 \\
25 Jul 1995 & 1.308 & 25 Jul 1995 & 1.30 \\
4 Jul 1992 & 1.29 & 29 Aug 1983 & 1.26 \\
14 Apr 2001 & 1.28 & 14 Apr 2001 & 1.22 \\
9 Apr 2001 & 1.20 & 18 May 1996 & 1.211 \\
1 Aug 1986 & 1.16 & 4 Jul 1985 & 1.205 \\
5 Jul 1980 & 1.111 & 1 Aug 1986 & 1.198 \\
11 Sep 2000 & 1.107 & 5 Jun 1985 & 1.193 \\
\hline
\end{tabular}

if the current reporting practices were applied to them. Of course, this is not possible and so we have no way to be certain about how accurately our detrending has accounted for the secular changes to the severe storm reports database.

Although our method for developing rankings is reproducible in the sense that it will always produce the same ranking from identical data, there is certainly subjectivity in the choice of weights, and even in the various choices of how the detrending was done. Furthermore, the overall methodology cannot be justified objectively; the use of a weighted linear combination of multiple variables is far from the only way to combine multiple variables. Like all reproducible methods, some subjectivity involving both the choice of scheme and in the choice of parameters for the chosen scheme is inevitable.

To the best of our knowledge, there has been no previous attempt to rank outbreak days consisting of primarily nontornadic severe convective storms. It can be observed that most of the high-ranking dates occur late in the warm season, including days in midsummer, whereas the dates for tornado outbreaks (Table 5) are spread widely through the year, except in midsummer. This suggests that widespread outbreaks of primarily nontornadic severe storms are often associated with large mesoscale convective systems during the warm season, whereas major tornado outbreaks are primarily spring and fall events. Although the tornado threat with summer convective systems is not vanishingly small, the occurrence of major tornado outbreaks in such events is unlikely, as is generally well known.

The distinction between major tornado outbreaks and major outbreaks of essentially nontornadic severe storms was incorporated into the methodology; cases considered for tornado outbreaks were excluded from consideration for primarily nontornadic severe weather outbreaks. Clearly, many events of a mixed character (i.e., both tornadic and nontornadic severe weather) occur, and many tornado outbreak days are also associated with numerous nontornadic severe storm reports. Consideration of these mixed events is outside the scope of this work, however.

Finally, we wish to reemphasize that while we have developed a ranking scheme for severe weather outbreaks, we have not claimed the scheme is intended to define an outbreak of severe weather. Our criteria were intended to serve our specific research goals and so we do not recommend that they be used to limit what constitutes a severe weather outbreak. For other goals, different criteria can be developed and used.

\section{REFERENCES}

Beebe, R. G., 1956: Tornado composite charts. Mon. Wea. Rev., 84, 127-142.

Blechman, J. B., 1975: The Wisconsin tornado event of April 21, 1974: Observations and theory of secondary vortices. Preprints, Ninth Conf. on Severe Local Storms, Norman, OK, Amer. Meteor. Soc., 344-349.

Brooks, H. E., 2004: On the relationship of tornado path length and width to intensity. Wea. Forecasting, 19, 310-319.

— C. A. Doswell III, and M. Kay, 2003: Climatological estimates of local daily tornado probability for the United States. Wea. Forecasting, 18, 626-640.

Bruening, S. L., M. P. Kay, and H. E. Brooks, 2002: A new perspective on the climatology of tornadoes in the United States. Preprints, 16th Conf. on Probability and Statistics, Orlando, FL, Amer. Meteor. Soc., J96-J103.

Doswell, C. A., III, R. H. Johns, and S. J. Weiss, 1993: Tornado forecasting: A review. The Tornado: Its Structure, Dynamics, Hazards, and Prediction, Geophys. Monogr., No. 79, Amer. Geophys. Union, 557-571.

— H. E. Brooks, and M. Kay, 2005: Climatological estimates of daily nontornadic severe thunderstorm probability for the United States. Wea. Forecasting, 20, 577-595.

Edwards, R., R. L. Thompson, K. C. Crosbie, J. A. Hart, and C. A. Doswell III, 2004: A proposal for modernized definitions of tornado and severe thunderstorm outbreaks. Preprints, $22 d$ Conf. on Severe Local Storms, Hyannis, MA, Amer. Meteor. Soc., CD-ROM, 7B.2.

Forbes, G. S., and R. M. Wakimoto, 1983: A concentrated outbreak of tornadoes, downbursts and microbursts, and implications regarding vortex classification. Mon. Wea. Rev., 111, 220-236. 
Fujita, T., 1974: Jumbo outbreak of 3 April 1974. Weatherwise, 27 (3), 116-126.

Galway, J. G., 1977: Some climatological aspects of tornado outbreaks. Mon. Wea. Rev., 105, 477-484.

Glickman, T. S., Ed., 2000: Glossary of Meteorology. 2d ed. Amer. Meteor. Soc., $782 \mathrm{pp}$.

McCaul, E. W., Jr., 1991: Buoyancy and shear characteristics of hurricane-tornado environments. Mon. Wea. Rev., 119, 19541978.

Pautz, M. E., 1969: Severe local storm occurrences, 1955-1967. ESSA Tech. Memo. WBTM FCST12, Washington, DC, 77 pp.

Schaefer, J. T., and R. Edwards, 1999: The SPC tornado/severe thunderstorm database. Preprints, 11th Conf. on Applied Climatology, Dallas, TX, Amer. Meteor. Soc., 603-606.

Speheger, D. A., C. A. Doswell III, and G. J. Stumpf, 2002: The tornadoes of 3 May 1999: Event verification in central Oklahoma and related issues. Wea. Forecasting, 17, 362-381.
Thompson, R. L., and M. D. Vescio, 1998: The destruction potential index-A method for comparing tornado days. Preprints, 19th Conf. on Severe Local Storms, Minneapolis, MN, Amer. Meteor. Soc., 280-282.

Van Tassel, E. L., 1955: The North Platte Valley tornado outbreak of June 27, 1955. Mon. Wea. Rev., 83, 255-264.

Verbout, S. M., L. M. Leslie, H. E. Brooks, and S. L. Bruening, 2004: Leveling the field for tornado reports through time: Inflation-adjustment of annual tornado reports and objective identification of extreme tornado reports. Preprints, $22 d$ Conf. on Severe Local Storms, Hyannis, MA, Amer. Meteor. Soc., CD-ROM, 7B.3.

Wolter, K., and M. S. Timlin, 1998: Measuring the strength of ENSO-How does 1997/98 rank? Weather, 53, 315-324.

Zipser, E. J., and J. H. Golden, 1979: A summertime tornado outbreak in Colorado: Mesoscale environment and structural features. Mon. Wea. Rev., 107, 1328-1342. 